\title{
OESTROUS CYCLE AND PRESENCE OF THE MALE IN WATER-DEPRIVED RATS*
}

\author{
O. BOTERO CORREA, I. M. LIBERMANN, A. CAPANO AND \\ P. CHIANCONE
}

Laboratory of Water and Salt Metabolism, Latin American Center of Perinatology and Human Development, Department of Physiopathology, School of Medicine, Hospital de Clínicas, piso 15, Montevideo, Uruguay

(Received 26th October 1971, accepted 3rd Fanuary 1972)

Summary. The effect of water deprivation on the oestrous cycle of albino rats was not modified by the presence of the male. Both in the absence and in the presence of the male, water-deprived rats became anoestrous. In early stages of water deprivation, $81 \%$ of the rats showed one complete cycle, after which they became anoestrous.

It has been shown that stimuli associated with presence of the male may have a marked influence on the reproductive behaviour of the female rat. Hughes (1964) observed that both a shortening of oestrous cycles and a synchronization of oestrus in the rat could be brought about by the presence of a male. Cooper \& Haynes (1967) and McNeilly, Cooper \& Crighton (1970) reported that the presence of the male had a significant effect on the inanition-induced increase in the cycle length of rats, bringing these animals into oestrus earlier than would otherwise have been expected.

In the course of the present study, it was observed that water-deprived rats became anoestrous (Libermann, Capano, Botero Correa \& Otegui, 1971). This condition was not modified by stimuli associated with the presence of the male.

Forty-eight adult, female, albino rats of our laboratory strain, weighing $199 \cdot 0 \mathrm{~g} \pm 5 \cdot 3 \mathrm{~S}$.E. with normal oestrous cycles of 4 to 5 days as determined by vaginal smears, were individually caged and kept under a regimen of $14 \mathrm{hr}$ light/10 hr darkness. The rats were randomly allocated to six equal groups, two of which were allowed to feed and drink water freely. Of these two groups, one was maintained in the presence of a male (CM), while the other was the control group without a male $(\mathrm{C})$. In the remaining four groups, the rats were deprived of water from the beginning of the experiment but free access to rat pellets (13\% water content) was allowed. These groups were associated with a male as follows: from the start of the experiment (Group DM1), after 4 days (Group DM4), after 8 days (Group DM8), and at no time for the remaining animals (Group D). The experiments were started simultaneously in all the animals without taking into consideration the stage of their cycle.

Mature males of the same strain not subjected to water deprivation were

* This work was presented in part at the '2as. Jornadas Uruguayas de Ciencias Fisiológicas', Solís, 18-20 December 1970, Uruguay. 
used. They were selected at random and placed with the female every night for a 12- to $15-\mathrm{hr}$ period. The female rats were weighed and vaginal smears were examined daily at 11.00 hours. Mating was determined by the presence of spermatozoa in the smear. The experiment was continued until the waterdeprived rats had lost about $40 \%$ of their initial body weight, which is considered the safety limit for survival.

TABLE 1

EFFECT OF WATER DEPRIVATION AND PRESENCE OF THE MALE ON GYCLIC BEHAVIOUR IN RATS

\begin{tabular}{|c|c|c|c|c|c|c|}
\hline & $C$ & $C M$ & $D$ & $D M 1$ & $D M 4$ & $D M 8$ \\
\hline $\begin{array}{l}\text { Experimental time } \\
\text { (days) }\end{array}$ & $12 \cdot 4 \pm 0 \cdot 8$ & $13 \cdot 2 \pm 0 \cdot 5$ & $11 \cdot 2 \pm 0 \cdot 9$ & $11 \cdot 4 \pm 0 \cdot 4$ & $12 \cdot 5 \pm 0 \cdot 7$ & $10 \cdot 5 \pm 0 \cdot 2$ \\
\hline $\begin{array}{l}\text { Weight loss or gain } \\
(\% \text { of initial } \\
\text { weight) }\end{array}$ & $5 \cdot 5 \pm 2 \cdot 4$ & $6 \cdot 1 \pm 2 \cdot 2$ & $-40 \cdot 4 \pm 0 \cdot 32$ & $-40 \cdot 6 \pm 0 \cdot 86$ & $-39 \cdot 6 \pm 0 \cdot 84$ & $-41 \cdot 1 \pm 0 \cdot 5$ \\
\hline $\begin{array}{l}\text { Cycle length during } \\
\text { control period }\end{array}$ & $4 \cdot 4 \pm 0 \cdot 2$ & $4 \cdot 2 \pm 0 \cdot 2$ & $4 \cdot 1 \pm 0 \cdot 1$ & $4 \cdot 0 \pm 0 \cdot 1$ & $4 \cdot 1 \pm 0 \cdot 0$ & $4 \cdot 0 \pm 0 \cdot 2$ \\
\hline $\begin{array}{l}\text { Length of the } \\
\text { first cycle after } \\
\text { experiment } \\
\text { began (days) }\end{array}$ & $3.9 \pm 0.2$ & $5 \cdot 1 \pm 1 \cdot 5$ & $4 \cdot 3 \pm 0 \cdot 2$ & $4 \cdot 2 \pm 0 \cdot 2$ & $4 \cdot 4 \pm 0 \cdot 3$ & $4 \cdot 3 \pm 0 \cdot 3$ \\
\hline $\begin{array}{l}\text { Student's } t \text { be- } \\
\text { tween paired } \\
\text { data }\end{array}$ & 1.8 N.S. & 1.00 N.s. & $1 \cdot 19^{\text {N.S. }}$ & 1.00 N.s. & 1.42 N.s. & 0.97 N.S. \\
\hline $\begin{array}{l}\text { No of rats with } \\
\text { complete cycles } \\
\text { after start of } \\
\text { experiment }\end{array}$ & 8 & 8 & 5 & 7 & 8 & 6 \\
\hline $\begin{array}{l}\text { No. of rats with } \\
\text { sperm. in } \\
\text { vaginal smear }\end{array}$ & - & 8 & - & 5 & 0 & 0 \\
\hline
\end{tabular}

Values are mean +S.E. N.S. = not significant.

Each of the following groups contained eight female rats: $\mathrm{G}=$ drinking water, without male; $\mathrm{GM}=$ drinking water, with the male; $\mathrm{DMl}=$ water-deprived, with the male from the start of the experiment; DM $4=$ water-deprived, with the male after 4 days of experiment; DM8 = waterdeprived, with the male after 8 days of experiment; $\mathrm{D}=$ water deprived, without male.

The results obtained are shown in Table 1. All the C-group rats showed normal regular cycles. The vaginal smears of the CM-group were not altered by the presence of the male; no significant changes were observed in the length of the cycles. The subsequent cycle length in three animals which had failed to mate during the first oestrus after association with the male was not different from that before association with the male. One GM rat had a 14-day oestrous cycle due to a longer period of dioestrus. Association with the male had no effect on the cyclic behaviour of the anoestrus-induced water-deprived rats. Twenty-six water-deprived females became anoestrous after they had completed one oestrous cycle; this cycle was recorded at the beginning of the experiment and its length did not differ significantly from the control period. The other six water-deprived animals showed no cyclic changes after the onset of the experiment. In all the rats, anoestrus was due to continuous dioestrus. 
The presence of the male at a later stage (Groups DM4 and DM8) did not alter the dioestrus state. The same proportion of water-deprived females showing cyclic activity was found in each individual group $\left(\chi_{3}^{2}\right.$ d.f. $\left.=3.99 ; P>0.25\right)$.

The average weight loss of the water-deprived animals was $11 \cdot 7 \% \pm 1 \cdot 3$ S.E. at the time of the first oestrus. The extent to which water deprivation induced abnormal cyclic behaviour varied among the rats. An average loss of $21.0 \% \pm$ 1.6 S.E. (range: 16.5 to $28.5 \%$ ) was observed at the time of expected oestrus in the six water-deprived females which had become anoestrous early in the experiment. Another six of the twenty-six water-deprived animals which showed one oestrous cycle lost between 16.4 and $30 \%$ of their weight at the time of oestrus. Thus, the effect of presence of the male on the cyclic behaviour of the water-deprived animals appeared not to be related to their weight loss.

Spermatozoa in the vaginal smears of the CM group were always found during pro-oestrus and oestrus. Five (DM1) rats mated at the time of oestrus, when their average weight loss was $7.4 \%$ (range: 4.5 to $12 \%$ ). Four waterdeprived animals (two of the DM1 and two of the DM4 groups) showed one complete oestrous cycle in the presence of the male, but spermatozoa were not found in their vaginal smears. At oestrus, these four rats had lost an average of $19.3 \%$ of their weight (range: 14.5 to $27.4 \%$ ). It would seem that a weight loss of about $15 \%$ must be produced in water-deprived animals at pro-oestrous or oestrus to cause refusal to accept the male. The remaining seventeen waterdeprived females that had completed one oestrous cycle were distributed as follows: five to Group D, six to Group DM4 and six to Group DM8. These animals were either without the male (D animals) or the male was introduced after the females had completed their oestrous cycle during water-deprivation. The weight loss in the latter animals was on the average $26.3 \%$ (range: 17.0 to $36.4 \%$ ) at the time when the male was brought into association with them. No spermatozoa were observed in the smears from these rats.

Weight loss in completely water-deprived rats is similar to that of those in acute starvation, since it is well known that thirsty rats decrease their food intake as do hungry rats their water intake (Wolf, 1958). During the first 4 days of water deprivation, our rats decreased their food intake to average levels that were $62 \%, 27 \%, 15 \%$ and $10 \%$, respectively, of the control levels. After that time, their food intake was between 6 and $2 \%$ of the control values. Thus, it is not easy to estimate the relative importance of water deprivation and starvation on the cycle length changes which were observed.

The finding that the prolonged dioestrus of our rats induced by water deprivation was not modified by the presence of a male was in disagreement with the results reported by Cooper \& Haynes (1967) in their $50 \%$ underfed animals whose weight losses were comparable to those in our study. The differences with the results reported by Cooper \& Haynes (1967) and Hughes (1964), who recorded a shortening in the cycle length of females in the presence of the male, could have been due to differences in the experimental design. The rats used by Hughes were allowed unrestricted access to water and food: Cooper \& Haynes used mildly underfed animals; our animals were completely waterdeprived.

It has been suggested that secretion of FSH and LH, which is blocked in 
mildly underfed rats, is revoked by the presence of a male (Cooper \& Haynes, 1967). Since anoestrus is a reversible condition in both acutely starved (Mulinos, Pomerantz, Smelser \& Kurzrok, 1939) and water-deprived rats (Libermann et al., 1971), we may suppose that animals submitted to such an acute stress as complete water-deprivation may show a stronger pituitary block than those undergoing progressive inanition. The presence of the male is not a strong enough stimulus to release the FSH and LH secretion thus blocked.

\section{REFERENCES}

COOPER, K. J \& HAYNES, N. B. (1967) Modification of the oestrous cycle of the under-fed rat associated with the presence of the male. F. Reprod. Fert. 14, 317.

Hughes, R. L. (1964) Effect of changing cages, introduction of the male, and other procedures on the oestrous cycle of the rat. C.S.I.R.O. Wildl. Res. 9, 115.

Libermann, I. M., Capano, A., Botero-Correa, O. \& Otegui, J. T. (1971) Modification in the estrous cycle of water-deprived and subsequently rehydrated rats. Acta physiol. latinoam. 21, 156.

MaNeilly, A. S., Cooper, K. J. \& Crighton, D. E. (1970) Modification of the oestrous cycle of the under-fed rat induced by the proximity of the male. F. Reprod. Fert. 22, 359 .

Mulinos, M. G., Pomerantz, L., Smelser, J. \& Kurzrox, R. (1939) Estrus-inhibiting effects of inanition. Proc. Soc. exp. Biol. Med. 40, 79.

Wolf, A. V. (1958) Thirst. Physiology of the urge to drink and problems of water lack, p. 110. Charles C. Thomas, Springfield, Illinois. 